\title{
Migración, seguridad y derechos humanos en la Unión Europea
}

\author{
Itzel Ethelvina Cruz-Pérez \\ Universidad Santiago de Compostela, España
}

\section{Resumen}

En este trabajo se abordan de manera descriptiva y analítica las acciones más importantes que se han impulsado en los últimos años, desde las instituciones comunitarias, para hacer frente a la "llegada" de refugiados a los Estados miembros de la Unión Europea. Podemos afirmar con base en la investigación que aquí se presenta que, a través del entramado normativo, existe una creciente y lamentable tendencia a considerar a los refugiados como una amenaza política, económica y social; enfocando más bien los esfuerzos en salvaguardar el denominado "espacio Schengen", así como sus fronteras externas poniendo en entredicho, aspectos fundamentales como la protección de los Derechos Humanos.

Palabras clave: Derechos Humanos, inmigración, seguridad, Unión Europea.

\section{Migration, security and Human Rights in the European Union}

\section{Abstract}

This paper address in a descriptive and analytical manner the most important actions that have been promoted in recent years, from the community institutions, to deal with the "arrival" of refugees in the Member States of the European Union. We can affirm based on the research presented here that, through the normative framework, there is a growing and lamentable tendency to consider refugees as a political, economic and social threat; focusing instead on efforts to safeguard the so-called "Schengen area", as well as its external borders, putting in question, fundamental aspects such as the protection of Human Rights.

Key words: Human Rights, immigration, security, European Union, Member States.

Recibido: 28 de enero de 2019

Aprobado: 20 de mayo de 2019 


\section{INTRODUCCIÓN}

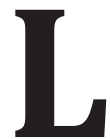

os movimientos a gran escala de refugiados y otros emigrantes forzosos se han convertido en uno de los fenómenos migratorios más importantes en el mundo contemporáneo; asimismo, han adquirido cada vez más una posición prominente en la agenda de la mayoría de los Estados alrededor del mundo, no sólo por el significado humanitario que tiene, sino también por sus repercusiones en los ámbitos político, económico, social; y podemos agregar, de seguridad en los países de acogida.

Según datos del Alto Comisionado de las Naciones Unidas para los Refugiados (ACNUR) "la población desplazada forzosamente en el mundo aumentó en 2017 (...) al finalizar el año 68.5 millones de personas se encontraban desplazadas forzosamente en todo el mundo" (2018a: 2) de los cuales 25.4 millones eran refugiados y 3.1 millones solicitantes de asilo; cifras alarmantes, pues continúan en aumento, alcanzando máximos históricos; no obstante, en el ámbito comunitario, en el 2017 en conjunto los Estados miembros de la Unión Europea

Registraron 728 mil 470 solicitudes de asilo, lo que representa una disminución de 44 por ciento en comparación con el 2016 y, es el segundo año consecutivo con menos solicitudes después de la afluencia sin precedentes del 2015 y 2016 (European Asylum Support Office (EASO), 2018).

Sin embargo, hay datos contrastantes a estas cifras, pues "las muertes en el mar Mediterráneo continúan representando el mayor número de muertes de migrantes en todo el mundo" (Organización Internacional para las Migraciones (OIM), 2017); “el 2017 cerró con 3 mil 081 personas desaparecidas en el Mediterráneo (...), desde 2014 se suman 15 mil 486 desaparecidas en el mar que separa el norte de África, Turquía y la península arábiga de las costas europeas" (ACNUR, 2018b). Otro dato importante, es que al finalizar el 2017 "por cuarto año consecutivo, Turquía albergaba al mayor número de refugiados en el mundo, con 3.5 millones de personas." (ACNUR, 2018a: 3).

Las numerosas migraciones forzadas que han sido provocadas por cuestiones como guerra, pobreza, inestabilidad política y económica, así como otras situaciones que dan lugar a emergencias complejas en 
los países vecinos de la Unión Europea, no parece que encuentren una solución pronta, especialmente ante la grave situación vivida en la República Árabe Siria, que continuó siendo el país con la mayor población de desplazados forzosos del mundo (ACNUR, 2018a: 6). Estos hechos nos ponen de manifiesto que, parece ser que las políticas de asilo e inmigración desplegadas por los Estados miembros y las instituciones comunitarias, encaminadas hacia una postura restrictiva y hacia el frenado de la inmigración mucho antes de entrar a su territorio se están viendo reflejadas en una disminución importante de llegadas, pero, ¿bajo qué costo?

Como ya es sabido, la Unión Europea ha trabajado desde hace años en el Sistema Europeo Común de Asilo (SECA), el cual se ha caracterizado por los grandes desequilibrios en su aplicación en la práctica entre los Estados miembros; y de manera más reciente en la Agenda Europea de Migración, que fue presentada por la Comisión Europea en 2015. Desde sus inicios, las políticas de asilo dentro de la Unión Europea han estado fuertemente vinculadas a los asuntos en materia de interior, especialmente en lo relativo al "espacio de libertad, seguridad y justicia"; ${ }^{1}$ es decir, a lo referente a la protección de las fronteras exteriores, así como salvaguardar el espacio Schengen, el cual ha sido uno de los logros más importantes de la Unión Europea, y que ante la llegada de refugiados se ha puesto en entredicho, considerando con ello a la presión migratoria como un desafío y sobre todo, para las instituciones ha supuesto una justificación para redoblar esfuerzos encaminados a proteger sus fronteras, sin importar las obligaciones de los Estados en los relativo a la protección de los derechos humanos de los inmigrantes y los principios de protección hacia las personas refugiadas.

Ante esto, resulta necesario analizar el enfoque adoptado a través de los instrumentos implementados para hacer frente a este fenómeno migratorio, el cual está fuertemente vinculado a muchos de los problemas más importantes que enfrenta el mundo hoy en día: la protección de los derechos humanos, la resolución de conflictos, la cooperación al desarrollo, entre otros.

1 La Unión Europea ha desarrollado un entramado legal para conformar un espacio de libertad, seguridad y justicia, vinculado a la libre circulación de personas y la seguridad de las fronteras. Se menciona en el Artículo 1B del Tratado de Ámsterdam "mantener y desarrollar la Unión como un espacio de libertad, seguridad y justicia, en el que esté garantizada la libre circulación de personas conjuntamente con medidas adecuadas respecto al control de las fronteras exteriores, el asilo, la inmigración (...)” (Unión Europea, 1997). 
Los objetivos de esta aportación son: I) Describir y analizar la hoja de ruta que ha implementado la Unión Europea para hacer frente a la llegada de refugiados. II) Analizar sobre todo el enfoque securitario que ha adoptado dicha respuesta — de manera específica en la Agenda Europea de Migración-y su repercusión a la luz de los derechos humanos, y III) Identificar los retos que ello supone y posibles rutas para el futuro. Para su argumentación se ha recurrido a una amplia literatura sobre el tema, al análisis de fuentes primarias, así como a la consulta del complejo entramado de normativa europea, especialmente lo relativo a nuestro objeto de estudio, así como otras fuentes de organismos competentes en la materia.

\section{ANTECEDENTES}

Existe un fuerte vínculo histórico entre los países europeos y los refugiados; dicho vínculo tiene sus orígenes principalmente en la Primera y Segunda Guerra Mundial, sucesos que influyeron en el movimiento masivo de personas en todo el continente y fuera de él. En el ámbito comunitario se han implementado diversos mecanismos para hacer frente al incremento de refugiados, situación que se acentúo desde la década de 1970, ante la llegada a Europa de un gran número de personas que huían de los conflictos internos de otros continentes. De manera paralela, los Estados miembros trabajaban en uno de sus proyectos más ambiciosos: La libre circulación de personas.

Como señala Huysmans "en la década de 1980, la migración fue cada vez más un tema de debates políticos sobre la protección del orden público y la preservación de la estabilidad interna" (2000: 756). En 1985, se logró alcanzar el Acuerdo Schengen, ${ }^{2}$ que en 1990 daría lugar al Acuerdo Operativo de Schengen, -en vigor desde 1995y el cual incluía procedimientos de asilo y exponía el estatus de los refugiados con más detalles y un sistema informatizado común para el intercambio de informaciones personales (Cerigioni, 2004: 5).

Los años siguientes se caracterizaron por una cooperación intergubernamental institucionalizada en materias de interés común como el derecho de asilo-, así como en el diseño de procedimientos para adoptar un conjunto de herramientas para desarrollar tal cooperación.

2 El primer acuerdo se firmó el 14 de junio de 1985, y lo hicieron solamente cinco países: Alemania, Bélgica, Francia, Luxemburgo y los Países Bajos. 
El giro vino con el Tratado de Ámsterdam —en vigor en 1999donde se dio una base legal a la prioridad de cooperar entre Estados en materia de asilo e inmigración, especificando que en un plazo de cinco años a partir de su entrada en vigor, se adoptarían medidas en materia de asilo, criterios y mecanismos para determinar el Estado miembro responsable de examinar la solicitud de asilo, normas mínimas para la acogida, entre otros aspectos (Tratado de Ámsterdam, Artículo $73 \mathrm{~K}$ ).

En 1999, el Consejo Europeo celebró una sesión especial en Tampere, que dio lugar al Programa Tampere, respecto a la creación de un espacio de libertad, seguridad y justicia en la Unión Europea; asimismo, se acordaron una serie de orientaciones y prioridades políticas entorno a la puesta en marcha del objetivo de Tampere. Dicho Programa se articuló en torno a una serie de temas prioritarios: una política de asilo y migración común de la Unión Europea, un auténtico espacio europeo de justicia, lucha contra la delincuencia a escala de la Unión y una acción exterior más firme. En mayo del mismo año empezaron las tareas para crear un Sistema Europeo Común de Asilo; teniendo como objetivo a corto plazo armonizar los marcos jurídicos de los Estados miembros mediante normas mínimas comunes. La primera fase del SECA (1999-2004) concluyó con la adopción de los instrumentos jurídicos pertinentes previstos en los Tratados (...) (Diario Oficial de la Unión Europea (DOUE), 2013: 1).

Al Programa de Tampere le sucedió el Programa de La Haya, que establece los objetivos que han de alcanzarse en el espacio de libertad, seguridad y justicia en el periodo 2005-2010, entre ellos: la lucha contra el terrorismo, definir un enfoque equilibrado de la inmigración, elaborar una gestión integrada de las fronteras exteriores de la Unión, establecer un procedimiento común en materia de asilo (Comisión Europea, 2009). Con el Programa de la Haya se definió que "el objetivo que debía perseguirse para establecer el SECA era la creación de un procedimiento común de asilo y un estatuto uniforme válido en toda la Unión" (DOUE, 2013: 1).

Posteriormente, el Tratado de Lisboa —en vigor en 2009— transforma en política común las medidas en materia de asilo. "Su objetivo no es solo el establecimiento de normas mínimas, sino también la creación de un sistema común que incluya estatutos y procedimientos uniformes" (Sy, 2017: 2). El Programa de Estocolmo, —aprobado por el Consejo Europeo el 10 de diciembre de 2009 para el periodo 2010-2014 - reafirmó que el establecimiento del SECA a más tardar 
en 2012, seguía siendo un objetivo político fundamental de la Unión y recordó que existían diferencias significativas entre las disposiciones nacionales y su aplicación (Consejo Europeo, 2010).

En los últimos años, el Espacio de Libertad, Seguridad y Justicia se ha enfrentado a importantes retos, sin duda, el más significativo el de la inmigración. En general, podemos destacar que, desde 1999 se han hecho esfuerzos importantes por crear un Sistema Europeo Común de Asilo como base normativa para armonizar las condiciones de acogida y otros aspectos vinculados al trato digno para las personas refugiadas; la aprobación definitiva del paquete de asilo por las instituciones de la Unión Europea en junio de 2013 marcó el inicio de etapa relevante en el establecimiento del SECA; este paquete incluía: Directiva sobre procedimientos de asilo revisada; ${ }^{3}$ Directiva sobre condiciones de acogida revisada; ${ }^{4}$ Directiva sobre requisitos; ${ }^{5}$ Reglamento de Dublín; ${ }^{6}$ Reglamento Eurodac. ${ }^{7}$

"Actualmente, el SECA se incluye en el marco jurídico del artículo 78 TFUE". ${ }^{8}$ (De Asis, 2017: 18) donde se especifica que "la Unión desarrollará una política común en materia de asilo (...) ajustándose a la Convención de Ginebra de 28 de julio de 1951 y al Protocolo de 31 de enero de 1967 (...)" (DOUE, 2012); así como, garantizar el respeto al principio de no devolución, ${ }^{9}$ y ofrecer un estatuto apropiado a los nacionales de terceros países ${ }^{10}$ que necesiten protección internacional.

3 Fecha de consulta 14 de agosto de 2018 en https://www.acnur.org/fileadmin/Documentos/BDL/2013/9260.pdf

4 Fecha de consulta 14 de agosto de 2018 en https://web.icam.es/bucket/DIRECTIVA\%2033\%202013\%20CONDICIONES\%20ACOGIDA\%20L00096-00116.pdf

5 Fecha de consulta 14 de agosto de 2018 https://web.icam.es/bucket/DIRECTIVA\%20 95\%202011\%20CALIFICACION\%20L00009-00026.pdf

6 Fecha de consulta 14 de agosto de 2018 en https://eur-lex.europa.eu/legal-content/ ES/TXT/PDF/?uri=CELEX:32013R0604\&rid=1

7 Fecha de consulta 14 de agosto de 2018 en https://eur-lex.europa.eu/legal-content/ ES/TXT/PDF/?uri=CELEX:32013R0603\&from=ES

8 Fecha de consulta 10 de agosto de 2018 en https://www.boe.es/doue/2010/083/ Z00047-00199.pdf

9 "La no devolución es un principio de Derecho internacional, refrendado por la Carta de los Derechos Fundamentales, en virtud del cual no se tomará ninguna medida de retorno a un lugar en el que se corra un grave riesgo de pena de muerte, tortura o tratos inhumanos o degradantes" (Comisión Europea, 2015: 12).

10 Se considera "nacional de un tercer país" cualquier persona que no sea ciudadano de la Unión en el sentido del Artículo 17, apartado 1, del Tratado y que no sea un beneficiario del derecho comunitario a la libre circulación con arreglo a la definición del artículo 2 , apartado 5, del Código de fronteras Schengen (DOUE, 2006). 


\section{SISTEMA EUROPEO COMÚN DE ASILO Y LA AGENDA EUROPEA DE MIGRACIÓN}

Como se puede apreciar en el apartado anterior, el camino hacia el logro del establecimiento del paquete de asilo que conforma el SECA no ha sido un camino fácil; sin embargo, ha sido aún más difícil el logro de su objetivo fundamental: la "homogeneización de las condiciones de acogida, de los procedimientos de asilo y de los criterios de reconocimiento de protección internacional en los países europeos" (Comisión Española de Ayuda al Refugiado (CEAR), 2017: 5). A pesar de los esfuerzos de las instituciones por armonizar las políticas de asilo, en la práctica se han demostrado grandes desequilibrios, especialmente en el 2015, año de gran afluencia de llegadas, pues "se registró un número récord de más de 1 millón 392 mil 155 solicitudes de protección internacional en la Unión Europea", de acuerdo con datos de la Oficina Europea de Apoyo al Asilo (EASO, 2016: 5) de las cuales 476 mil 510 se presentaron en Alemania; 177 mil 135 en Hungría; 162 mil 450 en Suecia; es decir, tres Estados miembros atendieron un 58 por ciento de las peticiones, generando un colapso social y político ante el aumento de solicitudes. Basta mirar la situación política actual de dichos países, donde partidos de extrema derecha se han aprovechado del discurso anti-inmigración para fortalecerse, encontrado apoyos.

En cuanto al porcentaje de reconocimiento se mostraron notables diferencias de criterio y de protección internacional; pues "de las 330 mil personas que obtuvieron protección internacional en la Unión Europea, casi la mitad la lograron en Alemania (148 mil 215)" (CEAR, 2016: 44), mientras que en algunos Estados miembros se mostraron bastante restrictivos; tal es el caso de España, en donde, de las casi "15 mil personas que formalizaron su solicitud de protección internacional (...) apenas 220 lograron el estatuto de refugiado" (CEAR, 2016: 57); provocando, entre otras cosas, que las personas solicitantes de asilo recibieran un tratamiento diferente en función del Estado miembro donde se presentara su solicitud; por lo que en el 2017, muchas más personas que buscaban refugio intentaban llegar a Alemania, donde de 1 millón 291 mil 785 de solicitudes en la Unión Europea, 745 mil 155 se hicieron en dicho Estado miembro, por lo que se hace evidente que el camino hacia el logro del SECA aún está lejos de su realidad.

Los Estados miembros a lo largo de los últimos años han mostrado una actitud restrictiva e insolidaria, evidentemente contraria al dis- 
curso emanado desde las instituciones y contraria a los esfuerzos de armonización del SECA. Podemos señalar que en parte, esta ineficacia se debe principalmente a que la legislación de la Unión Europea sobre asilo no ha sido aplicada de manera pertinente en los Estados miembros, quienes son en última instancia, responsables de la transposición de la legislación de asilo en sus ordenamientos internos; se han mantenido más bien las diferencias entre Estados en el proceso de decisión, así como en las tasas de solicitudes aceptadas. Es importante señalar que no ha sido una cuestión generalizada, pues algunos Estados miembros han avanzado en la aplicación del SECA; sin embargo, es evidente que un verdadero sistema de asilo, sólo puede ser efectivo a través de la aplicación plena por parte de todos los Estados miembros.

El año 2015 supuso un momento crucial en el seno de las instituciones europeas, ante una verdadera crisis en sus fronteras, pues aumentaron las cifras de inmigrantes fallecidos, sobre todo en el Mediterráneo donde se registraron 3 mil 771 víctimas (ACNUR, 2016). Asimismo, algunos Estados miembros se enfrentaron a un aumento importante en el número de llegadas a su territorio - a saber Grecia e Italia- tratándose principalmente de personas que cumplían con el perfil de refugiado. ${ }^{11}$ Esta situación obligó a las instituciones europeas a buscar alternativas para hacer frente a esta situación tan compleja a la que se enfrentaban estos Estados miembros, y sobre todo, ante la inoperancia del SECA.

Ante ello, en el 2015 la Comisión Europea presentó la Agenda Europea de Migración con el objetivo de implementar iniciativas concretas a mediano y largo plazo para dar respuesta a los diversos ámbitos de la inmigración en la Unión Europea. En aspectos generales, la Agenda Europea de Migración consta de una primera parte de respuestas inmediatas y de cuatro pilares para gestionar mejor la inmigración: I) reducir los incentivos para la migración irregular; II) salvar vidas y hacer seguras las fronteras exteriores; III) una política de asilo firme; y IV) una nueva política sobre la migración legal.

11 El concepto de refugiado viene recogido en el Artículo 1 de la Convención de Ginebra: "A los efectos de la presente Convención, el término refugiado se aplicará a toda persona que debido a fundados temores de ser perseguida por motivos de raza, religión, nacionalidad, pertenencia a determinado grupo social u opiniones políticas, se encuentre fuera del país de su nacionalidad y no pueda o, a causa de dichos temores, no quiera acogerse a la protección de tal país; o que careciendo de nacionalidad y hallándose fuera del país donde antes tuviera su residencia habitual, no pueda o, a causa de dichos temores, no quiera regresar a él" (Organización de las Naciones Unidas (ONU): 1951). 
En general, la Agenda Europea de Migración es un documento de gran importancia, pues constituye la hoja de ruta para los Estados miembros en materia de control de fronteras, seguridad, inmigración y asilo, para hacer frente a los desafíos actuales y futuros; no obstante, en el análisis de los diferentes documentos que emanan en el marco de la Agenda Europea de Migración surgen diversos cuestionamientos en relación al respeto y concordancia con la normativa en torno a los Derechos Fundamentales de las personas solicitantes de asilo y del Derecho Internacional de los Refugiados, para lo cual nos centraremos en los apartados siguientes.

\section{PRINCIPALES ENFOQUES DE LA AGENDA EUROPEA DE MIGRACIÓN}

En el primer apartado de la Agenda Europea de Migración se pretende responder a la situación en el Mediterráneo a través de acciones inmediatas; sin embargo, más que un verdadero interés de salvar vidas o de proteger a los inmigrantes, se observa un claro enfoque en fortalecer los mecanismos para evitar a toda costa su llegada. Estos objetivos de protección de las fronteras se canalizan principalmente a través de diversas acciones como: fortalecimiento y aumento del presupuesto de las operaciones conjuntas Tritón ${ }^{12}$ y Poseidón ${ }^{13}$ de Frontex ${ }^{14}$-de vigilancia fronteriza-, aumentando con ello sus medios y ámbito geográfico; operaciones en el marco de la Política Común de Seguridad y Defensa (PCSD) para hacer frente a las redes delictivas de traficantes; y a través de Europol reforzando su operación conjunta de información marítima Joint Operational Team Mare (JOT MARE) —de reciente creación - para combatir la inmigración ilegal que llega a la Unión Europea. Por otro lado, se enfatizó en la activación del mecanismo de intervención de emergencia previsto en el artículo 78, apartado 3, del TFUE (DOUE, 2012) que establece:

Si uno o varios Estados miembros se enfrentan a una situación de emergencia caracterizada por la afluencia repentina de nacionales de terceros países, el Consejo podrá adoptar, a propuesta de la Comisión, medidas provisionales en beneficio de los Estados miembros afectados (...).

12 "Apoya a Italia con control de fronteras, vigilancia, búsqueda y rescate en el Mediterráneo central (...)" (Comisión Europea, 2016a).

13 "Proporciona a Grecia asistencia técnica con el objetivo de fortalecer su vigilancia de fronteras, su capacidad para salvar vidas en el mar y sus capacidades de registro e identificación (...)" (Comisión Europea, 2016a).

14 Agencia europea para la Gestión de la operación operativa en las fronteras exteriores de los Estados miembros de la Unión Europea. 
Y que más adelante daría lugar a la "propuesta de Decisión del Consejo por la que se establecen medidas provisionales en el ámbito de la protección internacional en beneficio de Italia, Grecia y Hungría", ${ }^{15}$ con el objetivo de reubicar a personas con manifiesta necesidad de protección internacional desde Italia, Grecia y Hungría —15 mil 600; 50 mil 400; 54 mil respectivamente- en los demás Estados miembros. Así como la dotación para programas de desarrollo y protección en países de origen o de tránsito.

Por otro lado, en lo que concierne a los cuatro pilares de la Agenda Europea de Migración, se amplían los mecanismos que deben seguirse con miras a garantizar la disminución de llegadas a los Estados miembros y sobre todo, implementar acciones más contundentes para el retorno efectivo de nacionales de terceros países que, para la Unión Europea, no tienen derecho de permanecer en su territorio, considerándolos como un grave problema.

En el 1er. pilar reducir los incentivos a la inmigración irregular; destaca iniciativa de un Manual sobre retorno ${ }^{16}$ con el objetivo de garantizar la aplicación uniforme de normas y procedimientos en los Estados miembros para el retorno de nacionales de terceros países que se encuentren en situación irregular; y el seguimiento de la aplicación de la Directiva sobre el retorno, ${ }^{17}$ considerando que la funcionalidad imperfecta de las misma incentiva a más migrantes irregulares a viajar a la Unión Europea; además exige a países como Pakistán o Bangladesh a cumplir sus obligaciones respecto a la readmisión de sus nacionales a través de diversos proyectos piloto en materia de retorno. Se pone énfasis en el refuerzo y modificación de la base jurídica de Frontex en materia de retorno. En esta misma línea, se hace hincapié en fortalecer la ejecución de la Directiva sobre sanciones aplicables a los empleadores, ${ }^{18}$ que prohíbe el empleo de nacionales de terceros países que no tengan derecho a residir en la Unión Europea. Asimismo, menciona la asociación con los países de origen y de tránsito como un

15 Fecha de consulta: 21 de noviembre de 2018 en https://eur-lex.europa.eu/resource.html?uri=cellar:8c565a77-56ca-11e5-afbf-01aa75ed71a1.0008.02/DOC_1\&format=PDF

16 Más adelante daría lugar a la Recomendación de la Comisión de 1 de octubre de 2015 por la que se establece un «Manual de Retorno» común destinado a ser utilizado por las autoridades competentes de los Estados miembros en las tareas relacionadas con el retorno. Fecha de consulta: 20 de noviembre de 2018. Disponible en: http://ec.europa. eu/transparency/regdoc/rep/3/2015/ES/3-2015-6250-ES-F1-1.PDF

17 Fecha de consulta: 10 de febrero de 2019 en https://eur-lex.europa.eu/legal-content/ ES/TXT/PDF/?uri=CELEX:32008L0115\&from=ES

18 Fecha de consulta: 10 de noviembre de 2018 en https://eur-lex.europa.eu/legal-content/ES/TXT/PDF/?uri=CELEX:32009L0052\&from=FR 
aspecto crucial, señalando como buen ejemplo la asociación con Turquía, con quien, a través del financiamiento de la Unión Europea, dicho país realiza esfuerzos para hacer frente a la presión sobre su sistema de gestión de refugiados, evitando con ello peligrosas travesías en el Mediterráneo, o más bien evitando que lleguen.

En lo que se refiere al 2o. pilar gestión de las fronteras; nuevamente se hace énfasis en el reforzamiento del cometido y la capacidad de Frontex; la plena utilización de los sistemas informáticos existentes (Eurodac, Sistema de Información de Visados y Sistema de Información Schengen); así como el reforzamiento de las capacidades de terceros países clave para gestionar sus fronteras.

Respecto al 3er. pilar una política común de asilo, se centra sobre todo en cerrar aún más las posibilidades de solicitar asilo, considerando que existe un abuso en el sistema de asilo, pues en su mayoría de las solicitudes son infundadas, encontrando que determinadas nacionalidades son rechazadas en su totalidad. Por lo que se propone reforzar las disposiciones relativas a los países de origen seguros - ya bastante criticadas-, con el objetivo de hacer más rápida la tramitación de las solicitudes de asilo presentadas por personas originarias de países considerados seguros; es decir, su denegación rápida. Así como medidas destinadas a promover la identificación de los migrantes y la toma de huellas dactilares, sobre todo, para evitar movimientos secundarios dentro de la Unión Europea. Asimismo, se sugirió en este pilar la instauración de un nuevo sistema de seguimiento y evaluación del SECA para mejorar las normas relativas a las condiciones de acogida y los procedimientos de asilo presentes en los Estados miembros.

Por último, el 4o. pilar una nueva política de migración legal, aborda de manera general los intentos de reforzar los mecanismos ya existentes — como la tarjeta azul UE- ${ }^{19}$ para atraer trabajadores calificados; sin embargo, este 4o. pilar, como señala De Asis "refleja una visión eminentemente mercantilista de la inmigración que no responde a una realidad (...)" (2017: 34) del contexto migratorio, sobre todo, en dicha región del mundo. Asimismo, la falta de acuerdos en el ámbito actualmente refleja el nulo interés por implementar vías seguras para la inmigración; por ejemplo, la Comisión Europea señaló a finales del 2018 que "las negociaciones interinstitucionales sobre la propuesta

19 "En 2009 se adoptó la Directiva sobre la <<tarjeta azul UE >> con el fin de hacer de la Unión Europea un destino más atractivo para los trabajadores extranjeros altamente calificados y contribuir a reforzar la economía del conocimiento" (Comisión Europea, 2016b: 2). 
de reforma de la tarjeta azul se encuentran en estos momentos estancadas" (2018: 6).

\section{Discusión}

Como señala Going (2016) "en los últimos años, la Unión Europea ha demostrado una absoluta incapacidad para elaborar una política migratoria común, coherente y multidimensional"; a través del entramado normativo que se desprende en el marco de la Agenda Europea de Migración, se pone de manifiesto que las acciones por parte de la Unión Europea mantienen y refuerzan un enfoque eminentemente securitario en torno a la inmigración, implementando medidas para proteger sus fronteras y fortaleciendo las ya existentes, con el objetivo último de evitar la llegada de solicitantes de asilo y refugiados, pero también de los denominados migrantes económicos; asimismo, se ha puesto especial énfasis en centrar grandes esfuerzos en el retorno a sus países de origen de las personas que permanecen de manera ilegal en territorio de la Unión, considerándoseles una especie de criminales.

Es importante mencionar que esta línea de actuación no se ha desarrollado de manera reciente en el ámbito europeo, sino más bien, es una tendencia que se ha mantenido constante desde hace varios años. Lo que se pretende resaltar es que en la guía enmarcada en la Agenda Europea de Migración para los próximos años, se ha hecho más evidente, ignorando con ello diversas cuestiones cruciales, como la transformación de los factores que impulsan a las personas a salir de sus países, así como los beneficios que puede traer consigo la inmigración, de manera especial en la Unión Europea, donde se atraviesa por diversos retos demográficos, como el rápido envejecimiento de su población.

Por otro lado, una de las consecuencias más importantes de dicha postura europea, ha sido la violación por parte de los Estados miembros en su conjunto de muchas de las obligaciones internacionales en materia de Derechos Humanos. Como señala Gortázar (2017: 105):

El Derecho Internacional de los DDHH se trata de un compendio de normas (de ámbito universal y también de ámbito regional) que puede evitar que los Estados devuelvan a las personas a países de alto riesgo para su vida o su integridad, así como lograr que se les aseguren en el país de destino sus derechos fundamentales. 
A través de la revisión de las acciones puestas en marcha en los últimos años, se evidencia que no existe interés por parte de los líderes europeos en respetar incluso, elementales normas de derechos humanos; comenzando por los bastante cuestionables acuerdos con terceros países, ya sea enfocados en las readmisiones o en el financiamiento para gestionar sus fronteras ante la migración. Tal es el caso con Turquía, región que para muchos Estados miembros sigue sin considerarse un tercer país seguro; sin embargo, "el 29 de noviembre de 2015 (...) ambas partes activaron el Plan de Acción Conjunto (PAC)" (Comisión Europea, 2016c: 2) con el cual se pretendía, en aspectos generales, que a cambio de la financiación de tres millones de euros, Turquía aceptara el "retorno rápido de los migrantes que habían llegado hasta territorio europeo a través de Italia y Grecia; asimismo, Turquía se comprometía a controlar las fronteras externas de la Unión Europea y acoger a los refugiados que los Estados miembros ya no estaban dispuestos a recibir (Garcés y Sánchez, 2017).

Asimismo, a pesar de estas contradicciones entre Estados miembros, en septiembre del 2015, la Comisión Europea propuso una lista común de países seguros que incluía Albania, Bosnia y Herzegovina, ex República Yugoslava de Macedonia, Kosovo, Montenegro, Serbia y Turquía (Accem, 2016); no obstante, al siguiente año Turquía afrontaba un golpe de Estado contra el presidente Recep Tayyip Erdogan; y no sólo eso, diversas organizaciones de defensa de los Derechos Humanos han alertado de una crisis y vulneración de derechos humanos, sobre todo en contra de solicitantes de asilo en las fronteras de Turquía. Lo que hace irónico que esta región del mundo se considerara segura para las personas refugiadas; no obstante, Turquía se mantenía como un gran aliado para la Unión Europea en materia migratoria. De manera reciente, en abril del 2018, los miembros de la Comisión de Interior y Justicia del Parlamento Europeo han dejado a Turquía fuera de la lista de países seguros (La Vanguardia: 2018); sin embargo, durante estos años, los solicitantes de asilo han tenido que acatar la disposición de radicar en un Estado sin las garantías de protección pertinentes.

Desde la Agenda Europea de Migración, se enfatizaba como un ejemplo a seguir la asociación con Turquía, con intenciones de implementar acuerdos similares con Níger, Nigeria, Senegal, Malí y Etiopía; como señala Garcés "estos acuerdos significan también seguir con la externalización del control migratorio, es decir, que otros controlen por nosotros las fronteras" (2016). Otro aspecto importante de aná- 
lisis referente a la lista de países seguros hace referencia a que el rechazo masivo de personas por ostentar una determinada nacionalidad, vulnera el Artículo 3 de la Convención sobre el Estatuto de los Refugiados, que señala que "los Estados Contratantes aplicarán las disposiciones de esta Convención a los refugiados, sin discriminación por motivos de raza, religión o países de origen" (ONU, 1951).

En este mismo sentido, la Carta de los Derechos Fundamentales de la Unión Europea ${ }^{20}$ también señala en su Artículo 19.1 que "se prohíben las expulsiones colectivas" y en el Artículo 19.2 que "nadie podrá ser devuelto, expulsado o extraditado a un Estado en el que corra un grave riesgo de ser sometido a la pena de muerte, tortura o a otras penas o tratos inhumanos o degradantes". Así como el Artículo 4 del Protocolo $\mathrm{n}^{\circ} 4$ a la Convención Europea de Derechos Humanos ${ }^{21}$ "quedan prohibidas las expulsiones colectivas de extranjeros". A pesar de ello, se prefirió implementar mecanismos rápidos para agilizar el retorno de las personas que llegaban a territorio comunitario en búsqueda de protección internacional.

Más preocupante aún, ha sido que las organizaciones de defensa de los derechos humanos han alertado sobre el aumento en las agresiones y violaciones a los derechos humanos hacia los migrantes y refugiados, pues como señala en su Informe 2016/2017 de Amnistía Internacional "en varios países europeos se observó un aumento de los delitos de odio contra los solicitantes de asilo, musulmanes y extranjeros" (2017: 51) y de manera específica, ante la situación en Grecia se pronunciaban respecto a que "persistieron las denuncias de tortura y otros malos tratos infligidos por miembros de las fuerzas de seguridad" (Amnistía Internacional, 2017: 213); asimismo, las condiciones de recepción de las personas refugiadas, solicitantes de asilo y migrantes se caracterizaban por el hacinamiento y la insalubridad, la falta de seguridad suficiente y la incertidumbre respecto al futuro.

Por otro lado, puede considerarse como unos de los grandes fracasos comunitarios, la Directiva en torno a la reubicación de 120 mil refugiados — señalada anteriormente-, pues la Comisión Europea, a través del Informe sobre la aplicación de la Agenda Europea de Migración de marzo de 2018, ${ }^{22}$ hacía mención que un total de 11 mil

20 Consultado en http://www.europarl.europa.eu/charter/pdf/text_es.pdf el 22 de septiembre de 2018.

21 Consultado en: https://www.echr.coe.int/Documents/Convention_SPA.pdf el 22 de septiembre de 2018.

22 Comunicación de la Comisión al Parlamento Europeo, al Consejo Europeo y al Consejo. "Informe sobre la aplicación de la Agenda Europea de Migración. Consultado el 
999 personas habían sido reubicadas desde Italia y (...) 21 mil 847 personas habían sido reubicadas desde Grecia; es decir, solo un 28.2 por ciento. Asimismo, la Comisión informaba que había iniciado procedimientos de infracción en julio de 2016, y el 7 de diciembre de 2017 decidió denunciar a la República Checa, Hungría y Polonia ante el Tribunal de Justicia de la UE por incumplimiento de sus obligaciones legales, pues como señala De Asis, se trataba de "una decisión, la cual de acuerdo con el artículo 288 TFUE, es obligatoria en todos sus elementos" (2017: 25); no obstante, de igual forma la mayoría de los Estados miembros, se mostraron insolidarios, algunos ante la llegada de solicitantes de asilo "han llegado a levantar muros o vallas fronterizas (...), incluso han llegado a fijar cuotas de entrada de refugiados y de peticiones de asilo aceptables, lo que es incompatible con el derecho europeo e internacional" (Porras, 2017).

En este mismo sentido, señalar que uno de los golpes más fuertes para la Unión Europea, derivado de la crisis de refugiados ha sido la restricción de la libre circulación en el Espacio Schengen en algunos Estados, que en aplicación del Art. 23 del Código de Fronteras Schengen $^{23}$ referente al "restablecimiento temporal de los controles en las fronteras interiores", implantaron controles temporales internos, como: Alemania, Austria, Dinamarca, Francia, Noruega y Suecia; y otros más, como Hungría o Eslovenia, han levantado alambradas y desplegado al ejército (Mortera, 2016); ante ello la crisis de refugiados pareció ser una justificación para intensificar las acciones con un enfoque securitario para proteger las fronteras exteriores, el refuerzo amplio de Frontex lo demuestra; sin embargo, como señalan Espuche e Imbert "se ha ido reforzando sin ningún tipo de mecanismo eficaz para poder establecer su responsabilidad en caso de violación de derechos humanos" (2016: 30). Como se mencionó anteriormente, "la libre circulación de personas" se trata de uno de los logros más tangibles de la Unión, por lo que las instituciones han enfocado todos sus esfuerzos en el fortalecimiento de las fronteras exteriores.

Para algunos autores, el fracaso de las reubicaciones se debió a aspectos como: lentitud en los procedimientos de asilo, ya que en algunos Estados miembros el proceso puede demorar varios meses, inclu-

14 de septiembre de 2018 en https://eur-lex.europa.eu/resource.html?uri=cellar:c77176b2-277c-11e8-ac73-01aa75ed71a1.0003.02/DOC_1\&format=PDF

23 Reglamento (CE) No 562/2006. Fecha de consulta: 11 de junio de 2018 en http://www. exteriores.gob.es/Portal/es/ServiciosAlCiudadano/InformacionParaExtranjeros/Documents/C\%C3\%B3digo\%20de\%20fronteras\%20Schengen.\%20Parlamento\%20Europeo.pdf 
so años, "periodo durante el cual el solicitante se ve obligado a vivir en medio de una incertidumbre social y jurídica" (Berthiaume, 1995) ; así como el hecho de que no se tomara en cuenta incluso, circunstancias de los solicitantes, por ejemplo, los idiomas hablados, las redes de solidaridad (familia y comunidad nacional) y las oportunidades económicas (Espuche e Imbert, 2016: 27).

Asimismo, en el ámbito que nos concierne respecto a las violaciones de los Derechos Humanos, otro problema que se deriva de la llamada Fortaleza europea es que los recién llegados se enfrentan constantemente a discriminación, racismo, xenofobia, pues tampoco las políticas de integración han sido prioridad en muchos Estados miembros. Es importante mencionar, que en esta cuestión influyen muchas más cosas del ámbito político y social que merece la pena analizar, pues atiende a razones mucho más complejas. Lo que es cierto es que, el solicitante de asilo sigue siendo una persona vulnerable en los países de acogida dentro de la Unión Europea, pues los Estados miembros, mantienen desde hace años poco interés en implementar de manera efectiva la normativa europea en materia de asilo, lo que ha llevado al conjunto de la Unión a fortalecer en mayor medida la protección ante la llegada de refugiados.

Lo que hemos observado con las medidas implementadas en los últimos años, son: acciones contundentes para el retorno efectivo de nacionales de terceros países que mantienen una situación de "irregularidad; el rechazo creciente de solicitudes de asilo en las fronteras; trámites de asilo por vía rápida"; rastreo de barcos con inmigrantes evitando su llegada; identificación de contrabandistas de migrantes; menos vías de acceso seguras a la Unión Europea, lo que lleva a los solicitantes de asilo a hacer uso de las mafias, muchas veces poniendo en riesgo su vida y por supuesto sometiéndose a violaciones graves de los Derechos Humanos; los que llegan son trasladados a países vecinos donde se espera sea tramitada su solicitud de asilo.

Este último aspecto, hace surgir cuestionamientos respecto al respeto por parte de la comunidad europea al principio de non-refoulement, que prohíbe la vuelta de individuos a lugares donde se pueda temer tratamientos inhumanos o degradantes y persecución. Dicho principio se encuentra consagrado en la Convención sobre Refugiados de la ONU de 1951, además es un principio de ius cogens y pieza angular del Derecho de Asilo; no obstante, parece que se ha optado por esta herramienta para externalizar la responsabilidad, haciendo que 
otros Estados se enfrenten a una sobre demanda de asilo, como es el caso de Turquía. Esta situación era cuestión de tiempo, puesto que ya lo señalaba años atrás Crisp:

En los próximos años, los Estados (...) tratarán de utilizar su peso económico y diplomático para garantizar que los países de origen, en las regiones menos desarrolladas, vuelvan a admitir a los nacionales cuyas solicitudes de estatus de refugiado hayan sido rechazadas (2003).

\section{ConClusiones}

Como se mencionó al inicio de este trabajo, el objetivo consistía en analizar de manera detallada las acciones que se han promovido en los últimos años, desde las instituciones comunitarias, para hacer frente a los diversos retos en materia de refugio y asilo. Si bien, es un trabajo arduo y extenso, se lograron sintetizar algunas de las cuestiones más relevantes en el ámbito, y que sirven como base para entender la hoja de ruta que se pretende seguir en los años venideros en la región europea. Se considera pertinente y viable que desde el ámbito académico, se enfatice en la normativa internacional de los Derechos Humanos, pues parece que prima un olvido y desinterés en salvaguardar normas de larga data.

Derivado del análisis realizado en esta aportación, se pueden concluir diversos aspectos relevantes. Primero, dejar de manifiesto que si bien, a lo largo de los años, desde que comenzaron los esfuerzos por construir un espacio para la libre circulación de personas han estado fuertemente vinculados a las cuestiones de inmigración y asilo. La situación de inestabilidad en las regiones cercanas a la Unión Europea ha generado una oleada de personas que huyen de sus países, principalmente a causa de la guerra. Estos hechos han obligado a las instituciones a replantearse un escenario de actuación para hacer frente a diversos retos, pues algunos Estados miembros - sobre todo los que se encuentran en primera línea- se han enfrentado a un aumento considerable de llegadas de personas que cumplen con el perfil de refugiado. No obstante; la respuesta comunitaria ha hecho más evidente las acciones enfocadas en la protección de fronteras y sobre todo, una postura en contra de la inmigración. La denominada crisis de refugiados es más bien, una crisis de valores y de Derechos Humanos en la Unión Europea. A pesar de ser una de las regiones más desarrolladas del mundo, las fronteras comunitarias se han reforzado de manera re- 
ciente, tratando de evitar a toda costa la llegada de inmigrantes y en devolver a los que ya han llegado, evidenciando su enfoque securitario.

En la Agenda Europea de Migración, la cual pretende ser la hoja de ruta para los próximos años para los Estados miembros, es evidente el enfoque securitario, a través del fortalecimiento de los obstáculos de acceso a territorio comunitario, lo que ha desembocado sin duda en violaciones masivas de los Derechos Humanos en nombre de la lucha contra las mafias de traficantes. Esta línea de acción, sin duda es una cuestión bastante criticable en la política migratoria europea, pues parece no tomar en cuenta los numerosos beneficios que la inmigración puede reportar en los países destino, produciendo bienes económicos y en otros ámbitos, ya lo señala la OIM, en su Informe más reciente:

La inmigración puede producir un efecto positivo en el mercado laboral al incrementar la oferta de mano de obra en sectores y ocupaciones con escasez de trabajadores y ayudar a corregir desequilibrios del mercado de trabajo. Estos efectos positivos en el mercado de trabajo, también se observan en ocupaciones menos cualificadas (2018: 5).

Las causas de este repliegue por parte de la Unión Europea, sin duda son complejas y muy diversas; sin embargo, se puede señalar que estas acciones no hacen más que fomentar la intolerancia, discriminación y rechazo entre la sociedad de acogida, puesto que como señala De Asis:

Los Estados miembros han alzado muros, no sólo físicos sino también invisibles, en forma de medidas contrarias a la integración de los extranjeros y con el objetivo evidente de desincentivar la llegada de solicitantes de asilo (2017: 36).

En los medios de comunicación se ha mostrado como un colapso de llegadas, mostrándose como una invasión; no obstante, en el año 2015, cuando se consideró como una crisis de refugiados, las llegadas representaron el 0.27 por ciento comparado con la población de los 28 Estados miembros. En suma, dicho "proceso ha incluido múltiples actores, como gobiernos nacionales, bases populares, redes de policía transnacionales europeas, medios de comunicación, etc." (Huysmans, 2000).

Sin duda la Unión Europea, se ha convertido en uno de los principales destinos de las personas desplazadas a consecuencia, principalmente de las guerras, lo que ha influido en el apoyo a grupos partidis- 
tas de extrema derecha, quienes se han alimentado principalmente de esta brecha ante la percepción de una mala gestión por parte de las instituciones comunitarias; sin embargo, debemos de tener en cuenta, que estos movimientos se diferencian de aquellos por cuestiones económicas, por lo que, la reacción debería enmarcarse en los principios consagrados en las normas internacionales y comunitarias para la protección de los derechos de los refugiados, lo que requiere que se adopten las medidas necesarias para garantizar a las personas que huyen de sus países, un trato digno y las garantías de un procedimiento adecuado de su solicitud.

Las tendencias globales actuales, obligan a que los Estados sepan adaptarse a las transformaciones del fenómeno migratorio, pues los movimientos no cesarán, y sin duda la gestión que realice la Unión Europea en este ámbito será una cuestión decisiva en los próximos años; sobre todo si continúa optando por respuestas contrarias a la defensa de los Derechos Humanos y el Derecho Internacional de los Refugiados; "el control de las fronteras a cualquier precio está suponiendo la falta de criterios de transparencia (...), así como violaciones de la legalidad y de los Derechos Humanos de las personas migrantes" (Going, 2016).

\section{REFERENCIAS BIBLIOGRÁFICAS}

Accem. (2016). Nuevo listado UE de países seguros. Consultado el 12 de diciembre de 2018 en https://www.accem.es/nuevo-listado-ue-de-paises-seguros/

Alto Comisionado de las Naciones Unidas para los Refugiados. (ACNUR) (2016). 2016, record de muertes en el mar Mediterráneo. Consultado el 4 de octubre de 2018 en https://eacnur.org/es/actualidad/noticias/emergencias/2016-record-de-muertes-en-el-mar-mediterraneo

Alto Comisionado de las Naciones Unidas para los Refugiados. (ACNUR) (2018a). "Un repaso a 2017. Resumen de tendencias", Tendencias Globales, Desplazamiento Forzado en 2017. UNHCR. Suiza.

Alto Comisionado de las Naciones Unidas para los Refugiados. (ACNUR) (2018b). "Más de 15.000 personas desaparecidas en el Mediterráneo. Consultado el 10 de julio de 2018 en https://eacnurorg/es/actualidad/ noticias/emergencias/mas-de-15000-personas-desaparecidas-en-el-mediterraneo

Amnistía Internacional. (2017). "Informe 2016/2017. La situación de los Derechos Humanos en el mundo". Consultado el 14 de agosto de 2018 en 
https://www.amnesty.org/download/Documents/POL1048002017SPANISH.PDF.

Berthiaume. C. (1995). "Asylum under threat". Refugees Magazine. Issue 101.

Cerigioni, Elisabetta. (2004). “Fortaleza Europea. Comentarios a las políticas sobre refugiados en la Unión Europea". Gazeta de Antropología. Fecha de publicación: noviembre de 2004. Consultado el 23 de octubre de 2018 en http://www.ugr.es/ pwlac/G20_31Elisabetta_Cerigioni.pdf

Comisión Española de Ayuda al Refugiado. (CEAR) (2016). Informe 2016: las personas refugiadas en España y Europa. Consultado el 23 de diciembre de 2018 en http://www.ccar.cat/wp-content/uploads/2016/06/Informe-2016.pdf

Comisión Española de Ayuda al Refugiado. (CEAR) (2017). "Hacia dónde va el nuevo sistema europeo común de asilo: retos, amenazas y propuestas. CEAR. Consultado el19 de julio de 2018 en https://www.cear.es/ wp-content/uploads/2017/03/INFORME-SECA.pdf

Consejo Europeo. (2010). "Programa de Estocolmo. Una Europa abierta y segura que sirva y proteja al ciudadano". Consultado el 12 de agosto de 2018 en https://eur-lex.europa.eu/LexUriServ/LexUriServ.do?uri=0J:C:2010:115:0001:0038:ES:PDF

Comisión Europea. (2009). "Programa de La Haya: 10 prioridades para los próximos cinco años. Una asociación para la renovación europea en el ámbito de la libertad, la seguridad y la justicia". Consultado el 29 de julio de 2018, en https://eur-lex.europa.eu/legal-content/ES/TXT/?uri=LEGISSUM\%3Al16002

Comisión Europea. (2015). "Comunicación de la Comisión al Parlamento Europeo al Consejo, al Comité Económico y Social Europeo y al Comité de las Regiones. Una Agenda Europea de Migración". Consultado el 13 de julio de 2018 en http://ec.europa.eu/transparency/regdoc/rep/1/2015/ ES/1-2015-240-ES-F1-1.PDF

Comisión Europea. (2016a). EU operations in the Mediterranean sea. Consultado el 21 de diciembre de 2018 en https://ec.europa.eu/home-affairs/ sites/homeaffairs/files/what-we-do/policies/securing-eu-borders/factsheets/docs/20161006/eu_operations_in_the_mediterranean_sea_en.pdf

Comisión Europea. (2016b). Propuesta de Directiva del Parlamento Europeo y del Consejo relativa a las condiciones de entrada y residencia de nacionales de terceros países con fines de empleo de alta capacitación. SWD(2016) 194 final.

Comisión Europea. (2016c). Informe de la Comisión al Parlamento Europeo y al Consejo. Plan de acción conjunto UE-Turquía - Tercer informe de ejecución. Consultado el 19 de diciembre de 2018 en https://eur-lex.europa.eu/legal-content/ES/TXT/PDF/?uri=CELEX:52016DC0144\&rid=41 
Comisión Europea. (2018). Comunicación de la Comisión al Parlamento Europeo y al Consejo. Fortalecer las vías legales hacia Europa: un componente indispensable de una política migratoria equilibrada y global. Consultado el 1 de septiembre de 2018 en https://eur-lex.europa.eu/LexUriServ/LexUriServ.do?uri=COM:2018:0635:FIN:ES:PDF

Crisp, Jeff. (2003). A new asylum paradigm? Globalization, migration and the uncertain future of the international refugee regime. UNHCR. Consultado el 21 de febrero de 2019 en https://www.unhcr.org/research/working/3fe16d835/new-asylum-paradigm-globalization-migration-uncertain-future-international.html

De Asis, Francisco. (2017). La Agenda de Migración: últimos desarrollos". Revista Electrónica de Estudios Internacionales. Consultado el 22 de septiembre de 2018 en http://www.reei.org/index.php/revista/num33/notas/agenda-europea-migracion-ltimos-desarrollos

Diario Oficial de la Unión Europea. (2006). Reglamento del Parlamento Europeo y del Consejo de 15 de marzo de 2006 por el que se establece un Código comunitario de normas para el cruce de personas por las fronteras. Consultado el 20 de febrero de 2019 en https://eur-lex.europa.eu/ legal-content/ES/TXT/PDF/?uri=CELEX:32006R0562\&from=ES

Diario Oficial de la Unión Europea. (2012). Versión Consolidada del Tratado de Funcionamiento de la Unión Europea. Consultado el 15 de diciembre de 2018 en https://eur-lex.europa.eu/legal-content/ES/TXT/PDF/?uri=CELEX:12012E/TXT\&from=ES

Diario Oficial de la Unión Europea. (2013). Reglamento (UE) $n^{\circ}$ 604/2013 del Parlamento Europeo y del Consejo, de 26 de junio de 2013. Consultado el 14 de agosto de 2018 en https://eur-lex.europa.eu/legal-content/ES/ TXT/PDF/?uri=CELEX:32013R0604\&rid=1

Espuche, Brigitte e Imbert, Louis. (2016). De la crisis de los refugiados/as, a la crisis de Europa. Consultado el 3 de agosto de 2018 en http://www. academia.edu/31082119/De_la_crisis_de_los_refugiados_as_a_la_crisis_ de_Europa

European Asylum Support Office. (EASO) (2016). Annual report on the situation of asylum in the EU. Consultado el 10 de junio de 2018 en https:// www.easo.europa.eu/ information-analysis/annual-report

European Asylun Support Office. (EASO) (2018). The situation of asylum in the EU 2017: Overview. Consultado el septiembre de 2018 en https:// www.easo.europa.eu/overview-situation-asylum-eu-2017

Garcés, Blanca. (2016). Más externalización del control migratorio". Centro de Estudios y Documentación Internacionales de Barcelona. Consultado el 10 de junio de 2018 en https://www.cidob.org/es/publicaciones/serie_de_publicacion/opinion/migraciones/mas_externalizacion_del_control_migratorio 
Garcés, Blanca y Sánchez, Elena. (2017). "El acuerdo UE-Turquía, un año después. Mucho más que externalización". CIDOB. Consultado el 27 de agosto de 2018 en https://www.cidob.org/es/publicaciones/serie_de_ publicacion/opinion/europa/el_acuerdo_ue_turquia_un_ano_despues_ mucho_mas_que_externalizacion

Going, Juan Manuel. (2016). "Inmigración, asilo y refugio ante los retos actuales de la política exterior europea". Revista de Derecho UNED. Consultado el 23 de febrero de 2019 en http://revistas.uned.es/index.php/ RDUNED/article/view/16881

Gortázar, Cristina. (2017). "La protección de los refugiados por causas de la guerra y la respuesta de la Unión Europea". Sal Terrae. vol. 105(105), pp. 391-404. Consultado el 11 de noviembre de 2018 en http://hdl.handle.net/11531/22696

Huysmans, Jef. (2000). "The European Union and the Securitization of Migration" Journal of Common Market Studies. Consultado el 21 de febrero de 2019 en https://onlinelibrary.wiley.com/doi/pdf/10.1111/14685965.00263

La Vanguardia. (2018). Eurodiputados dejan a Turquía fuera de la lista de países seguros para asilo. Consultado el 20 de diciembre de 2018 en https://www.lavanguardia.com/politica/20180425/442998254531/ eurodiputados-dejan-a-turquia-fuera-de-la-lista-de-paises-seguros-para-asilo.html

Mortera, Camino. (2016). "Cómo salvar Schengen." Centre for European Reform. Consultado el 04 de junio de 2018 en https://www.cer.eu/ in-the-press/c\%C3\%B3mo-salvar-schengen

Organización de las Naciones Unidas. (ONU) (1951). Convención sobre el estatuto de los refugiados. Consultado el 15 de febrero de 2019 en https:// www.acnur.org/5b0766944.pdf

Organización Internacional para las Migraciones. (OIM) (2017). Se contabilizan 150.982 llegadas y 2,839 muertes en el Mediterráneo en 2017. Consultado el 28 de octubre de 2018 en https://www.iom.int/es/news/ se-contabilizan-150982-llegadas-y-2839-muertes-en-el-mediterraneo-en-2017

Organización Internacional para las Migraciones. (OIM) (2018). "Informe sobre las migraciones en el mundo 2018". Fecha de consulta: 04 de junio de 2018 en https://publications.iom.int/system/files/pdf/wmr_2018_ sp.pdf

Porras, José María. (2017). "El Sistema Europeo Común de Asilo y la crisis de los refugiados. Un nuevo desafío de la globalización". Revista de Estudios Políticos. Consultado el 11 de noviembre de 2018 en https://recyt. fecyt.es/index.php/RevEsPol/article/view/55906/33790 
Sy, Sarah. (2017). "La política de aislo". Parlamento Europeo. Consultado el 26 de septiembre de 2018 en http://www.europarl.europa.eu/RegData/ etudes/fiches_techniques/2013/051202/04A_FT(2013)051202_ES.pdf

Unión Europea. (1997). "Tratado de Ámsterdam”. Oficina de Publicaciones Oficiales de las Comunidades Europeas. Consultado el 16 de agosto de 2018 en https://europa.eu/european- union/sites/europaeu/files/ docs/body/treaty_of_amsterdam_es.pdf

\section{RESUMEN CURRICULAR DE LA AUTORA}

Itzel Ethelvina Cruz Pérez

Estudiante del Doctorado en Marketing Político, Actores e Instituciones de las Sociedades Contemporáneas en Facultad de Ciencias Políticas y Sociales de la Universidad de Santiago de Compostela, España. En la misma Universidad concluyó el Máster en Estudios Internacionales (2015). Licenciada en Ciencias Políticas y Administración Pública por la Universidad Autónoma del Estado de México (UAEM); asimismo, en la UAEM, laboró como Encargada de la Oficina de Representación en España (2014-2017) y como Jefa del Departamento de Gestión de Proyectos Internacionales de la Secretaría de Cooperación Internacional (2017-2018).

Correo electrónico: itzelcruz1730@gmail.com

itzelethelvina.cruz@rai.usc.es 